\title{
Mechanical criterion for coal and gas outburst: a perspective from multiphysics coupling
}

\author{
Ting Liu ${ }^{1,2} \cdot$ Baiquan $\operatorname{Lin}^{1} \cdot$ Xuehai $\mathrm{Fu}^{2} \cdot$ Ang Liu $^{3}$
}

Received: 9 February 2021/Revised: 6 April 2021/Accepted: 11 June 2021/Published online: 27 June 2021

(C) The Author(s) 2021

\begin{abstract}
Although a series of hypotheses have been proposed, the mechanism underlying coal and gas outburst remains unclear. Given the low-index outbursts encountered in mining practice, we attempt to explore this mechanism using a multiphysics coupling model considering the effects of coal strength and gas mass transfer on failure. Based on force analysis of coal ahead of the heading face, a risk identification index $C_{\mathrm{m}}$ and a critical criterion $\left(C_{\mathrm{m}} \geq 1\right)$ of coal instability are proposed. According to this criterion, the driving force of an outburst consists of stress and gas pressure gradients along the heading direction of the roadway, whereas resistance depends on the shear and tensile strengths of the coal. The results show that outburst risk decreases slightly, followed by a rapid increase, with increasing vertical stress, whereas it decreases with increasing coal strength and increases with gas pressure monotonically. Using the response surface method, a coupled multi-factor model for the risk identification index is developed. The results indicate strong interactions among the controlling factors. Moreover, the critical values of the factors corresponding to outburst change depending on the environment of the coal seams, rather than being constants. As the buried depth of a coal seam increases, the critical values of gas pressure and coal strength decrease slightly, followed by a rapid increase. According to its controlling factors, outburst can be divided into stress-dominated, coal-strength-dominated, gas-pressure-dominated, and multi-factor compound types. Based on this classification, a classified control method is proposed to enable more targeted outburst prevention.
\end{abstract}

Keywords Coal and gas outburst $\cdot$ Critical criterion $\cdot$ Multiphysics coupling $\cdot$ Response surface method

Ting Liu

mtkcliuting2013@163.com

1 School of Safety Engineering, China University of Mining \& Technology, Xuzhou 221116, China

2 Key Laboratory of CBM Resources and Dynamic Accumulation Process, China University of Mining \& Technology, Xuzhou 221008, China

3 Department of Energy and Mineral Engineering, G3 Center and EMS Energy Institute, The Pennsylvania State University, University Park, PA, USA

\section{Introduction}

Coal and gas outburst (hereafter referred to as outburst) is a destructive disaster that occurs during underground mining, involving violent and spontaneous ejections of gas and coal-rock materials from the mining space (Ma et al. 2020a, b; Guan et al. 2009; Zou et al. 2020; Wu et al. 2020). Since the first recorded outburst occurred in the Isaac Coal Mine in France in 1834, more than 40,000 outbursts have been reported around the world in more than 20 countries, including the US, China, and Germany (Fan et al. 2017; Ma et al. 2020a, b), with China most affected (Zou et al. 2020). Outburst and its resultant secondary disasters can result in serious casualties and property loss (An et al. 2019; Zhai et al. 2016; Zhou et al. 2020). On April 25, 2019, an outburst occurred in Sanjin coal mine in 
Yunnan Province, killing four miners and leading to a direct economic loss of up to 39.35 million CNY.

Outburst risk is closely related to mining depth. There is a critical buried depth (initial outburst depth) at which an outburst begins to occur in a given coal seam. When the buried depth of a coal seam exceeds the initial outburst depth, the risk and intensity of an outburst generally increase with increasing mining depth (Zhai et al. 2016). In recent years, a phenomenon of low-index outburst with increased mining depth has been observed; this refers to cases where an outburst occurs although the seam had been identified as non-outburst prone based on current indices. This phenomenon is difficult to prevent and can lead to serious loss. Therefore, elucidating the mechanism of outburst, especially low-index outburst, will be conducive to the prediction and prevention of such disasters (An et al. 2019; Yang et al. 2021).

The mechanism of outburst has been studied since 1852, and many hypotheses have been proposed to explain it (Ma et al. 2020a, b; Rudakov and Sobolev 2019; Sobczyk 2011, 2014; Zhi and Elsworth 2016). Most of the models or hypotheses can be classified as pocket models, dynamic models, or multi-factor model (Guan et al. 2009). According to pocket models, there exists a gas-rich and loose zone in front of the working face, and outburst occurs once the gas-rich pocket is uncovered. However, such models can only explain certain special cases encountered in mining practice. A dynamic model assumes that mining disturbance weakens the coal ahead of the working face, which makes it prone to outburst. However, this hypothesis overemphasizes the effects of stress while ignoring the key factor of gas. The multi-factor model proposes that outburst is co-initiated by multiple factors, including geostress, gas pressure, coal strength, and mining disturbance (Ma et al. 2020a, b; An et al. 2019).

In recent decades, progress has been made regarding the mechanism of outburst. Guan et al. (2009) drew an analogy between outburst and magma fragmentation during volcanic eruption. This model considered outburst as an eruption driven by a gas pressure difference, but it ignored other factors such as stress and coal strength. Chen (2011) suggested a domino effect that led to instantaneous outburst, based on the assumption that choked flow in the fracture zone resulted in a large gas pressure gradient, which initiated an outburst. The author claimed that this model could successfully predict all the observed phenomena preceding outbursts. Cao et al. (2020) investigated the initiation and evolution of outburst with micro-fracture mechanics. In this study, pre-set fractures parallel to the working face were assumed to undergo opening, expansion, and propagation driven by gas pressure. This process was modeled by setting a criterion assuming that outburst occurred once the fracture length exceeded the host element dimension. Based on analyses of the external environment of outbursts, Shu et al. (2017) proposed a key structural body model of outbursts. Based on this model, a mechanical criterion and an energy criterion for outburst initiation were developed. Fan et al. (2017) suggested that outburst was caused by interactions among coal-gas media, the geology dynamic environment, and mining disturbance, and developed a stress-seepage-damage coupling model to simulate the evolution of the outburst dynamic system. Based on this system, they also proposed a formation criterion for the geological dynamic system, an instability criterion, and an energy criterion (Luo et al. 2018). Lu et al. (2019) proposed an energy criterion for outbursts under deformed and normal coal combinations. Combining this with a coupled fluid-solid model, they simulated the distribution and components of energy ahead of the working face. An et al. (2019) found that coal damage had an effect on gas expansion energy during outburst initiation. Based on fractal theory, they modified the existing models of gas desorption and gas expansion energy.

Although previous research has clearly shown that stress, gas pressure, and coal strength are the main factors controlling outbursts, there have been few reports on how these factors interact with each other to induce outburst. In addition, most of the previously proposed hypotheses only give qualitative descriptions of the initiation mechanism; few quantitative studies have been reported.

In this work, we attempt to clarify the mechanism of outburst from a multiphysics coupling perspective. First, based on the equivalent fractured coal model, a multiphysics coupling model is developed and verified. Next, a risk identification index and critical criterion are proposed to determine the risk and initiation of outburst. Using the coupled model, factors influencing the risk identification index are systematically studied. Finally, a mechanism of multiphysics-coupling-induced outburst is described and a classified control method is proposed.

\section{Modeling}

\subsection{Constitutive stress-strain equation}

The deformation of coal containing methane can generally be expressed by Eq. (1), considering pore pressure and sorption-induced swelling (Liu et al. 2020a):

$G u_{i, k k}+\frac{G}{1-2 v} u_{k, k i}-\alpha p_{f i}-\beta p_{m i}-K \Delta \varepsilon_{m i}^{s}+F_{i}=0$

where, $G$ is the shear modulus of coal, $G=E / 2(1+v)$; $E$ is the elastic modulus of coal; $v$ is the Poisson's ratio of coal; $F_{i}$ is the body force in the $i^{\text {th }}$ direction; $\alpha$ and $\beta$ are Boit's coefficients of the fracture and the pore, 
respectively, $\alpha=1-K / K_{\mathrm{f}}, \beta=1-K / K_{\mathrm{s}} ; p_{\mathrm{f}}$ and $p_{\mathrm{m}}$ are the gas pressures in the fracture and the matrix, respectively; $K$ is the bulk modulus of coal, $K=E / 3(1-2 v)$; and $\varepsilon_{\mathrm{m}}^{\mathrm{s}}$ is the matrix strain induced by gas sorption, $\varepsilon_{\mathrm{m}}^{\mathrm{s}}=\varepsilon_{\mathrm{L}} p_{\mathrm{m}} /\left(p_{\varepsilon}+p_{\mathrm{m}}\right)$, with $\varepsilon_{\mathrm{L}}$ the Langmuir-type strain constant and $p_{\varepsilon}$ the Langmuir-type pressure constant.

Owing to disturbance by mining, failure often occurs in coal ahead of the working face. In this work, the DruckerPrager matching Mohr-Coulomb criterion was adopted to describe coal failure ahead of the working face:

$F-\left(\sqrt{J_{2}}-\alpha_{\mathrm{D}-\mathrm{P}} I_{1}-k_{\mathrm{D}-\mathrm{P}}\right)=0$

where, $J_{2}$ is the second deviatoric stress invariant and $I_{1}$ is the first stress invariant. Here, $\alpha_{\mathrm{D}-\mathrm{P}}$ and $k_{\mathrm{D}-\mathrm{P}}$ are material constants given by Eq. (3):

$$
\left\{\begin{array}{r}
\alpha_{\mathrm{D}-\mathrm{P}}=\frac{2 \sin \phi}{\sqrt{3}(3-\sin \phi)} \\
k_{\mathrm{D}-\mathrm{P}}=\frac{2 \sqrt{3} C \cos \phi}{(3-\sin \phi)}
\end{array}\right.
$$

where $C$ and $\phi$ are the cohesion and the internal friction angle, respectively.

In addition to shear failure, tensile failure can occur in a coal seam during the mining process. The failure criterion for tensile failure of coal can be expressed by Eq. (4):

$f_{\mathrm{t}}=-\sigma_{1}^{\mathrm{eff}}-\sigma_{\mathrm{t}}$

where, $\sigma_{\mathrm{t}}$ is the tensile strength of coal, and the minus sign indicates the tensile stress; when $f_{\mathrm{t}} \geq 0$, coal failure occurs.

\subsection{Changes in coal strength during mining}

\subsubsection{Cohesion and internal friction angle}

Given a set of stress-strain curves obtained under different confining stresses, the strength parameters of coal at and after the peak can be calculated. The detailed process can be found in reference (Jing et al. 2018).

Figure 1 shows the cohesion and the internal friction angle corresponding to peak and residual points calculated using 15 groups of stress-strain curves collected from the literature. As shown in Fig. 1a, all the cohesion values corresponding to the residual points are lower than those of the peak points, indicating that the decrease in cohesion after the peak represents a universal law. Relative changes in cohesion ranged between $30 \%$ and $90 \%$, with an average of $59.8 \%$, demonstrating that cohesion decreases greatly after failure. As shown in Fig. 1b, most of the increments in internal friction angle were in the range of $\pm 10 \%$, with an average of $-4.3 \%$. This implies that the internal friction angle does not change significantly after coal failure and can thus be considered as a constant.
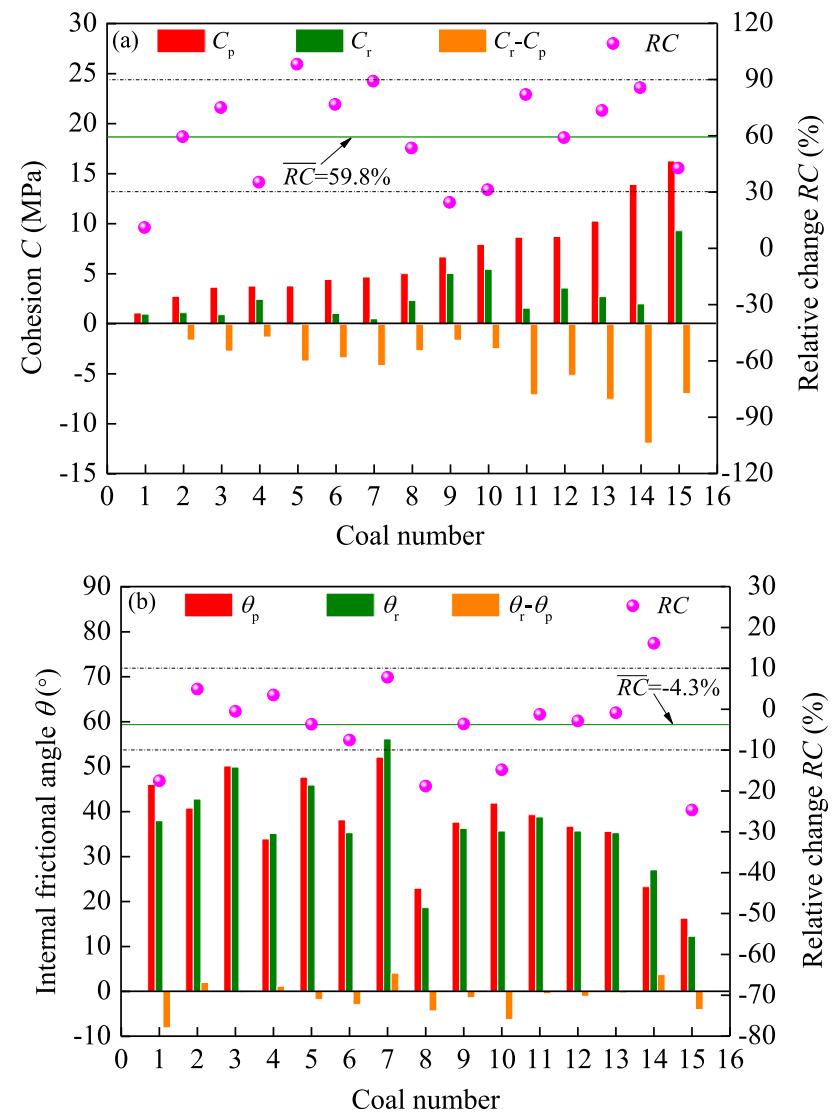

Fig. 1 Statistical results for cohesion and internal friction angle. $\left(C_{\mathrm{r}^{-}}\right.$ $\left.C_{\mathrm{p}}\right)$ and $\left(\theta_{\mathrm{r}}-\theta_{\mathrm{p}}\right)$ are the differences in cohesion and internal friction angle between residual and peak points, respectively; $R C$ indicates relative change: $R C=\left(C_{\mathrm{r}^{-}} C_{\mathrm{p}}\right) / C_{\mathrm{p}}$ or $R C=\left(\theta_{\mathrm{r}^{-}}-\theta_{\mathrm{p}}\right) / \theta_{\mathrm{p}}$

A series of models have been developed to quantify the relationship between cohesion and plastic strain, including models based on the exponential function, quadratic function, linear function, and some complex composite functions ( $\mathrm{Li}$ et al. 2016). Jing et al. (2018) theoretically proved that cohesion changed linearly with hoop strain in the plastic softening zone. In this work, a linear relation between cohesion and equivalent plastic strain is adopted (Alonso et al. 2003):

$C=\left\{\begin{array}{cc}C_{0}-\left(C_{0}-C_{\mathrm{r}}\right) \frac{\gamma^{\mathrm{p}}}{\gamma^{\mathrm{p} *}}, & 0 \leq \gamma^{\mathrm{p}} \leq \gamma^{\mathrm{p} *} \\ C_{\mathrm{r}}, & \gamma^{\mathrm{p}}>\gamma^{\mathrm{p} *}\end{array}\right.$

where $C$ is the cohesion of coal, $C_{0}$ is the initial cohesion of coal, $C_{\mathrm{r}}$ is the residual cohesion, $\gamma^{\mathrm{p}}$ is the equivalent plastic strain, and $\gamma^{\mathrm{p} *}$ is the equivalent plastic strain at the start of the residual stage.

\subsubsection{Tensile strength}

Assuming that coal follows the Mohr-Coulomb criterion and is in the uniaxial tensile state, we have 


$$
\sigma_{1}=\sigma_{2}=0, \quad \sigma_{3}=\sigma_{t}
$$

When the coal is in the triaxial tension state, the shear stress imposed is 0. Assuming that the Mohr circle is tangent to the yield surface, where coal is in the ultimate tensile state, we can obtain its tensile strength (Chen and Jin 2012) as follows:

$$
\sigma_{t}=\frac{2 C}{\tan \phi+\sqrt{1+\tan ^{2} \phi}}
$$

\subsection{Quantitative characterization of mining-disturbed coal}

Quantitative characterization of the coal structure is among the most important problems that arises in the study of gas flow in a mining-disturbed coal seam. To solve this problem, an equivalent fractured coal model was proposed in our previous work (Liu et al. 2020b). In this model, the generation of new fractures is viewed as a segmentation of the matrix, and the mining-disturbed coal can be viewed as an elastomer containing a smaller matrix and more fractures. Figure 2 shows a diagram of the equivalent fractured coal model and its application in describing the coal structure ahead of the working face.

Based on the equivalent fractured model, the matrix size in mining-disturbed coal seam can be quantified by Eq. (8) (Liu et al. 2021):

$L_{m}=\frac{1}{n_{\text {matrix }}+1} L_{\mathrm{m} 0}=\frac{\phi_{\mathrm{f} 0}}{\varepsilon_{\mathrm{b}}^{\mathrm{p}}+\phi_{\mathrm{f} 0}} L_{\mathrm{m} 0}$

where, $L_{\mathrm{m} 0}$ is the initial matrix size, $n_{\text {matrix }}$ is the number of new fractures in the specified direction of the matrix, $\varepsilon_{\mathrm{b}}^{\mathrm{p}}$ is the plastic strain of coal, and $\phi_{\mathrm{f} 0}$ is its initial fracture porosity, with $\phi_{\mathrm{f} 0}=3 L_{\mathrm{f} 0} / L_{\mathrm{m} 0}$ (Liu et al. 2017; Wu et al. 2011).

\subsection{Governing equation of gas migration in coal matrix}

In virgin coal seams, mass transfer between coal matrices and fractures can be expressed by Fick's law (Fan et al. 2019):

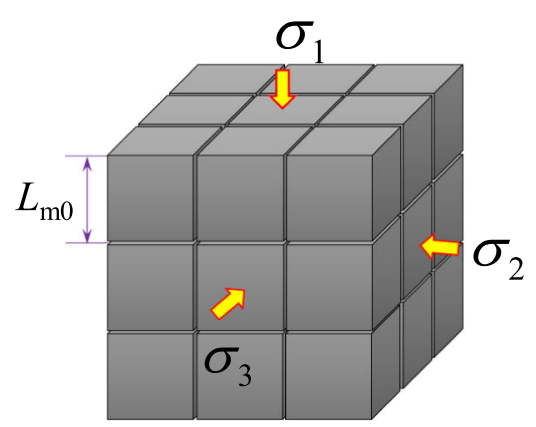

(a) Primary coal

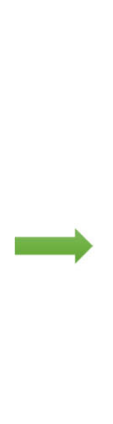

(b) Coal disturbed by mining

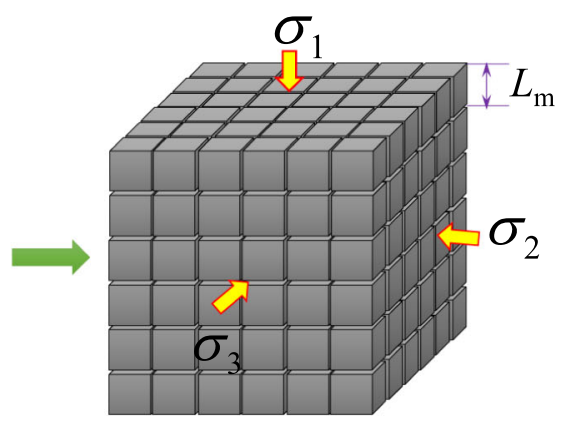

(c) Equivalent fractured coal

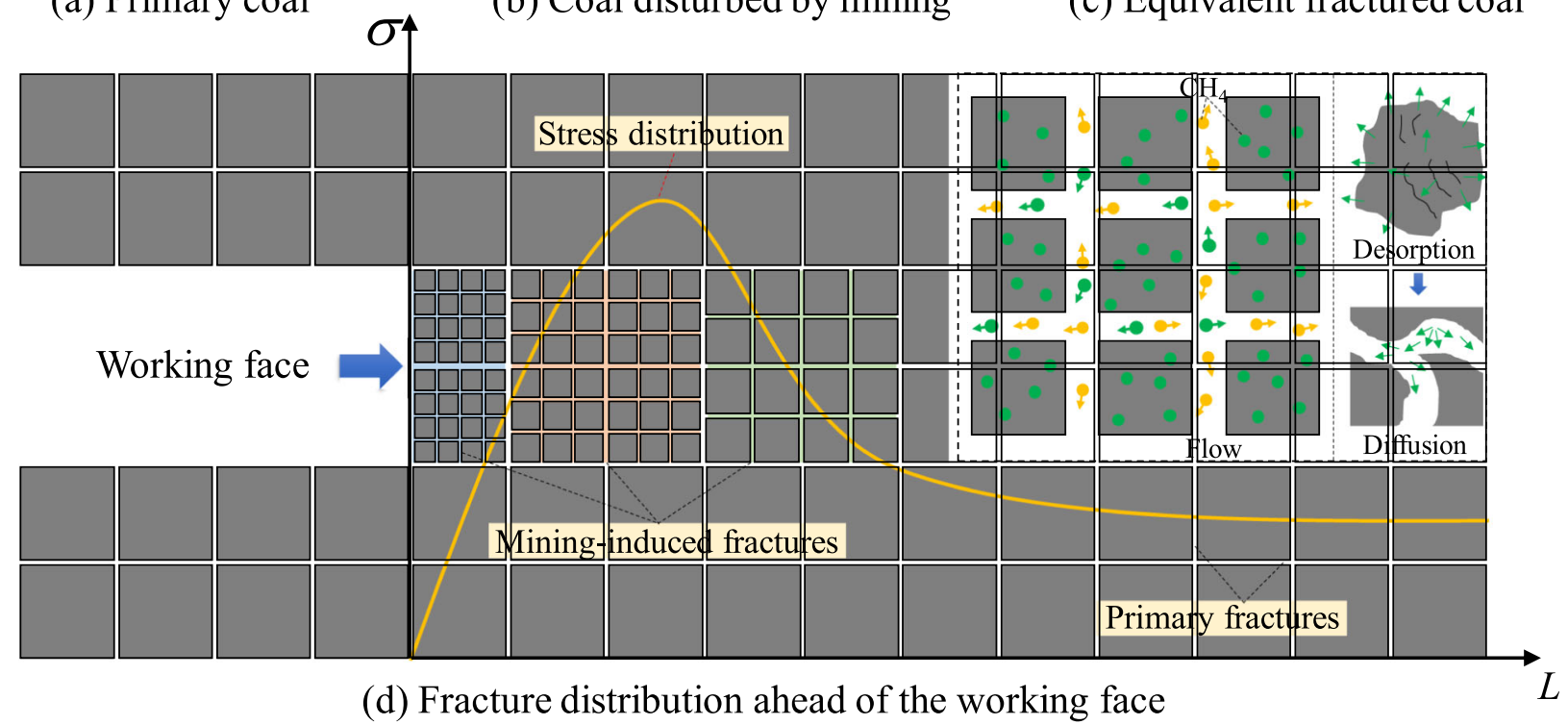

Fig. 2 Equivalent fractured coal model and its application in fracture characterization ahead of the working face. a primary coal; b coal disturbed by mining; c equivalent fractured coal; $\mathbf{d}$ fracture distribution ahead of the working face 
$Q_{\mathrm{m}}=\frac{1}{\tau} \frac{M_{\mathrm{C}}}{R T}\left(p_{\mathrm{m}}-p_{\mathrm{f}}\right)$

where, $Q_{\mathrm{m}}$ is the mass transfer capacity; $M_{\mathrm{C}}, R$, and $T$ are the molar mass of $\mathrm{CH}_{4}$, the gas constant, and the temperature of the coal seam, respectively; $\tau$ is the sorption time, $\tau=L_{\mathrm{m}}^{2} /\left(3 \pi^{2} D\right)$; and $D$ is the gas diffusivity of coal.

Mining disturbance changes the structure of the coal ahead of the working face, which in turn alters the diffusion path of gas in the matrix. The sorption time of miningdisturbed coal can be expressed by Eq. (10):

$\tau=\left(\frac{\phi_{\mathrm{f} 0}}{\varepsilon_{\mathrm{b}}^{\mathrm{p}}+\phi_{\mathrm{f} 0}}\right)^{2} \cdot \frac{L_{\mathrm{m} 0}^{2}}{3 \pi^{2} D}=\left(\frac{\phi_{\mathrm{f} 0}}{\varepsilon_{\mathrm{b}}^{\mathrm{p}}+\phi_{\mathrm{f} 0}}\right)^{2} \cdot \tau_{0}$

where, $\tau_{0}$ is the sorption time of a virgin coal seam.

Based on mass conservation, a governing equation for gas diffusion in virgin coal seams was developed (Lu et al. 2019). Combining this with Eq. (10), we can further obtain the governing equation of gas diffusion in mining-disturbed coal seams:

$$
\begin{aligned}
\frac{\partial}{\partial t} & \left\{\frac{M_{\mathrm{C}} \rho_{\mathrm{c}}}{V_{\mathrm{m}}} \cdot \frac{V_{\mathrm{L}} p_{\mathrm{m}}}{p_{\mathrm{L}}+p_{\mathrm{m}}}+\phi_{\mathrm{m}} \frac{M_{\mathrm{C}} p_{\mathrm{m}}}{R T}\right\} \\
& =-\left(\frac{\phi_{\mathrm{f} 0}+\varepsilon_{\mathrm{b}}^{\mathrm{p}}}{\phi_{\mathrm{f} 0}}\right)^{2} \cdot \frac{1}{\tau_{0}} \cdot \frac{M_{\mathrm{C}}}{R T}\left(p_{\mathrm{m}}-p_{\mathrm{f}}\right)
\end{aligned}
$$

where $\rho_{\mathrm{c}}$ is the coal density, $V_{\mathrm{m}}$ is the molar volume of gas, $V_{\mathrm{L}}$ and $p_{\mathrm{L}}$ are Langmuir constants, and $\phi_{\mathrm{m}}$ is the matrix porosity.

\subsection{Governing equation of gas flow in fracture}

The change in gas content in a fracture is the difference between the gas inflow and outflow (Danesh et al. 2016). Combining Darcy's law and Eq. (10), we can obtain the following controlling equation for gas flow in fractures in mining-disturbed coal seams:

$$
\begin{array}{r}
\phi_{\mathrm{f}} \frac{\partial p_{\mathrm{f}}}{\partial t}+p_{\mathrm{f}} \frac{\partial \phi_{\mathrm{f}}}{\partial t}-\nabla\left(\frac{k}{\mu} p_{\mathrm{f}} \nabla p_{\mathrm{f}}\right) \\
=\left(\frac{\phi_{\mathrm{f} 0}+\varepsilon_{\mathrm{b}}^{\mathrm{p}}}{\phi_{\mathrm{f} 0}}\right)^{2} \cdot \frac{1}{\tau_{0}} \cdot\left(p_{\mathrm{m}}-p_{\mathrm{f}}\right)
\end{array}
$$

where, $\mu$ is the dynamic viscosity of $\mathrm{CH}_{4}$ and $k$ is the coal permeability.

\subsection{Coupling term}

We have developed a porosity model of a mining-disturbed coal seam that considers the effects of stress change, matrix shrinkage, and coal failure, which has been shown in Eq. (13). In this model, when the coal is in the elastic stage, the porosity is dominated by the stress change and matrix shrinkage. At the strain-softening stage, porosity increases sharply because of the coal failure, whereas no obvious change occurs in the residual stage (Liu et al. 2021):

$\frac{\phi_{\mathrm{f}}}{\phi_{\mathrm{f} 0}}= \begin{cases}\frac{\phi_{\mathrm{f} 0}+\varepsilon_{\mathrm{b}}^{\mathrm{p}}}{\phi_{\mathrm{fi} 0}}\left(1-\frac{3}{\phi_{\mathrm{f} 0}}\left(\varepsilon_{\mathrm{m}}^{\mathrm{s}}-\varepsilon_{\mathrm{m} 0}^{\mathrm{s}}\right)-\frac{\Delta \sigma^{\mathrm{eff}}}{K_{\mathrm{f}}}\right) & \left(\varepsilon_{\mathrm{b}}^{\mathrm{p}} \leq \varepsilon_{\mathrm{bc}}^{\mathrm{p}}\right) \\ \frac{\phi_{\mathrm{f} 0}+\varepsilon_{\mathrm{bc}}^{\mathrm{p}}}{\phi_{\mathrm{f} 0}}\left(1-\frac{3}{\phi_{\mathrm{f} 0}}\left(\varepsilon_{\mathrm{m}}^{\mathrm{s}}-\varepsilon_{\mathrm{m} 0}^{\mathrm{s}}\right)-\frac{\Delta \sigma^{\mathrm{eff}}}{K_{\mathrm{f}}}\right) & \left(\varepsilon_{\mathrm{b}}^{\mathrm{p}}>\varepsilon_{\mathrm{bc}}^{\mathrm{p}}\right)\end{cases}$

where, $\phi_{\mathrm{f}}$ is the fracture porosity, $\varepsilon_{\mathrm{bc}}^{\mathrm{p}}$ is the plastic volumetric strain corresponding to the starting point of the residual stage, $\Delta \sigma^{\text {eff }}$ is the increment of effective stress, and $K_{\mathrm{f}}$ is the bulk modulus of fractures (the subscript ' 0 ' indicates the initial value).

According to the cubic law, the permeability of the coal seam can be described by Eq. (14) (Liu et al. 2021):

$\frac{k}{k_{0}}=\left(\frac{\phi_{\mathrm{f}}}{\phi_{\mathrm{f} 0}}\right)^{3}= \begin{cases}{\left[\frac{\phi_{\mathrm{f} 0}+\varepsilon_{\mathrm{b}}^{\mathrm{p}}}{\phi_{\mathrm{f} 0}}\left(1-\frac{3}{\phi_{\mathrm{f} 0}}\left(\varepsilon_{\mathrm{m}}^{\mathrm{s}}-\varepsilon_{\mathrm{m0}}^{\mathrm{s}}\right)-\frac{\Delta \sigma^{\text {eff }}}{K_{\mathrm{f}}}\right)\right]^{3}} & \left(\varepsilon_{\mathrm{b}}^{\mathrm{p}} \leq \varepsilon_{\mathrm{bc}}^{\mathrm{p}}\right) \\ {\left[\frac{\phi_{\mathrm{f} 0}+\varepsilon_{\mathrm{bc}}^{\mathrm{p}}}{\phi_{\mathrm{f} 0}}\left(1-\frac{3}{\phi_{\mathrm{f} 0}}\left(\varepsilon_{\mathrm{m}}^{\mathrm{s}}-\varepsilon_{\mathrm{m} 0}^{\mathrm{s}}\right)-\frac{\Delta \sigma^{\mathrm{eff}}}{K_{\mathrm{f}}}\right)\right]^{3}} & \left(\varepsilon_{\mathrm{b}}^{\mathrm{p}}>\varepsilon_{\mathrm{bc}}^{\mathrm{p}}\right)\end{cases}$

To solve the gas diffusion equation in a matrix, it is necessary to consider matrix porosity. In this work, the matrix porosity model developed in Liu et al. (2020a) is adopted:

$\phi_{\mathrm{m}}=\phi_{\mathrm{m} 0} \exp \left\{\frac{1-\phi_{\mathrm{m} 0}}{\phi_{\mathrm{m} 0}}\left[\varepsilon_{\mathrm{m}}^{\mathrm{s}}-\varepsilon_{\mathrm{m} 0}^{\mathrm{s}}-\frac{\Delta \sigma_{\mathrm{e}}}{K_{\mathrm{m}}}\right]\right\}$

where, $\phi_{\mathrm{m} 0}$ is the initial porosity of the matrix and $K_{\mathrm{m}}$ is the bulk modulus of the matrix.

\subsection{Mechanical criterion for outburst}

Outburst is a result of mechanical instability of coal ahead of the working face, arising under the combined action of crustal stress and gas pressure. In this section, a critical criterion for outburst during roadway excavation is developed by analyzing the stress imposed on a representative element volume (REV) of coal ahead of the working face.

During roadway excavation, the redistribution of stress and gas pressure leads to instability of coal near the working face (Fig. 3a). To explore the critical conditions for coal instability, we analyzed the stress distributions along the heading direction of the working face using a REV of coal of unit size (Fig. 3a). This analysis shows that stress and gas pressure increments constitute the driving force behind an outburst (Fig. 3b), while the resistance depends on the shear and tensile strengths of coal (Fig. 3c). The critical condition for instability of a REV can be written as 


$$
\begin{aligned}
& \left(\sigma_{x}+\frac{\mathrm{d} \sigma_{x}}{\mathrm{~d} x}\right)-\sigma_{x}+\left(p_{x}+\frac{\mathrm{d} p_{x}}{\mathrm{~d} x}\right)-p_{x} \geq 2\left(\sigma_{y} \tan \phi+C\right) \\
& \quad+2\left(\sigma_{z} \tan \phi+C\right)+\sigma_{t}
\end{aligned}
$$

where $\sigma_{x}, \sigma_{y}$, and $\sigma_{z}$ are stresses along the $x-, y$-, and $z$ directions, respectively; $x$ is the distance from the coal wall; and $p_{x}$ is the gas pressure at the point with coordinate $x$.

Rewriting Eq. (16), we obtain the critical criterion for coal instability ahead of the working face:

$$
C_{\mathrm{m}}=\frac{\frac{\mathrm{d} \sigma_{x}}{\mathrm{~d} x}+\frac{\mathrm{d} p_{x}}{\mathrm{~d} x}}{2 \tan \phi\left(\sigma_{y}+\sigma_{z}\right)+4 C+\sigma_{\mathrm{t}}} \geq 1
$$

where, $C_{\mathrm{m}}$ is the risk identification index of the outburst (if $C_{\mathrm{m}}<1$, the system remains stable; if $C_{\mathrm{m}}=1$, the system is in a state of critical instability; and if $C_{\mathrm{m}}>1$, the system is not stable).

Equation (17) shows that driving force behind an outburst consists of gradients of horizontal stress and gas pressure along the heading direction of the roadway, rather than the horizontal stress and gas pressure themselves. The risk of outburst rises as the gradients of horizontal stress and gas pressure increase. The resistance is mainly derived from the stresses perpendicular to the heading direction, the shear strength of the coal or the coal-rock interface, and the tensile strength of the coal. It is clear from Eq. (17) that the greater the stresses perpendicular to the heading direction, the more stable the coal. However, increases in $\sigma_{y}$ and $\sigma_{z}$ cause changes in $\sigma_{x}$, resulting in failure of the coal seam, which in turn increases the outburst risk. Therefore, the effects of stress on outburst risk are complex and should be analyzed based on the specific situation. Moreover, as the shear and tensile strengths of coal increase, the risk of outburst decreases; in previous research, the effect of tensile strength was often ignored, which may overestimate the outburst risk.

\section{Case study of outburst and model verification}

\subsection{Introduction of outburst case study}

From April 1991 to January 1992, 286 m of roadway (J1513,170 machine and equipment roadways) was excavated in No. 8 coal mine of Pingdingshan Coal Co., Ltd, in Henan Province, China. During this period, eight outbursts occurred, with an average frequency of 2.8 per $100 \mathrm{~m}$ of roadway. The intensity of coal outburst and volume of gas were $781 \mathrm{t}$ and $41,900 \mathrm{~m}^{3}$, respectively, with mean outburst intensity and gas volume of $97.6 \mathrm{t}$ and $5237.5 \mathrm{~m}^{3}$, respectively. The dynamic effects of these outbursts are obvious. Support deformation and downward movement were observed several times; the most prominent type of outburst was extrusion, which accounted for $87.5 \%$ of the total. Before the outbursts, a series of precursors were observed, including coal and gas blowout from boreholes, increases in gas emission, and coal bedding disorder.

Figure 4 shows the locations of the eight outbursts. The J15-13,170 machine and equipment roadways were located in the lower section of the J15-13,170 working face, with an opening elevation of $-490.29 \mathrm{~m}$ and buried depth of $566.0 \mathrm{~m}$. The thickness and dip angle of the coal seam in this area were $3.5-4.0 \mathrm{~m}$ and $16^{\circ}$, respectively, and the roof and floor were sandy mudstone with poor permeability.

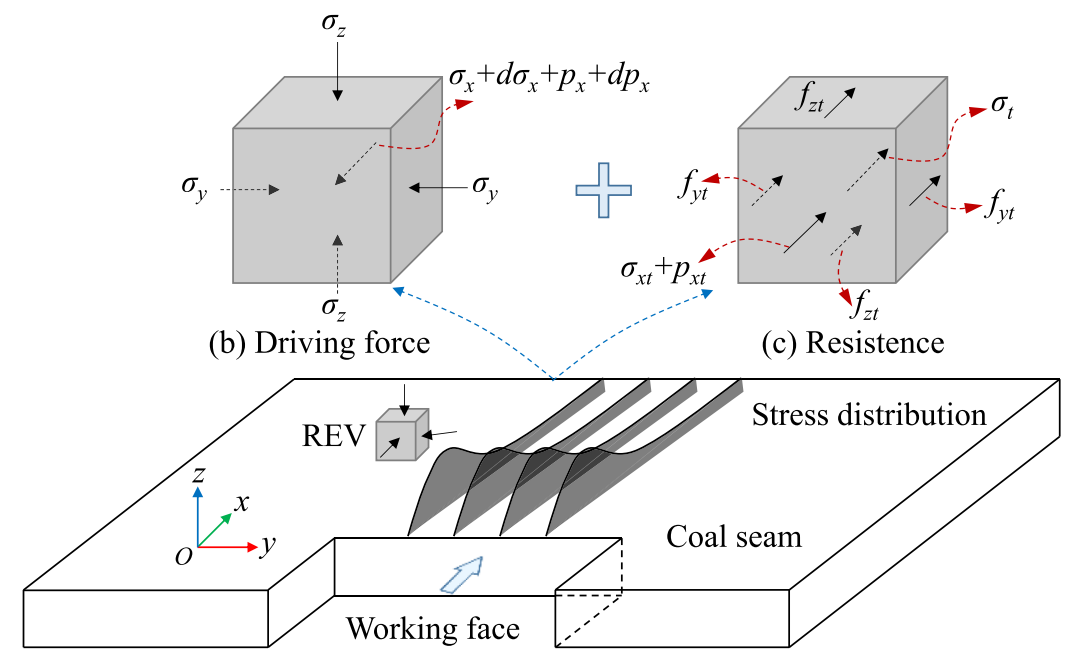

(a) Stress distribution in front of the working face

Fig. 3 Stress analysis of REV ahead of the working face 
The gas pressure and gas content were 1.47 MPa and $10.08 \mathrm{~m}^{3} / \mathrm{t}$, respectively.

\subsection{Case analysis and model verification}

Based on the eight outbursts that occurred in the J1513,170 machine and equipment lanes in No. 8 coal mine, we explored the cause of the frequent outbursts in this location from the perspective of multiphysics coupling. We also compared the results calculated with the new model and those obtained with the model ignoring the effect of coal failure.

Figure 5 shows the physical model used to simulate outbursts. The model was $30 \mathrm{~m}$ in both length and width, and $14 \mathrm{~m}$ in height. The thickness of the coal seam, roof, and floor were 4,5 , and $5 \mathrm{~m}$, respectively. The size of the excavated zone was $4 \mathrm{~m} \times 3.2 \mathrm{~m} \times 2 \mathrm{~m}$. The top of the model was set as the stress boundary with a constant stress of $15 \mathrm{MPa}$ to simulate a buried depth of approx. $550 \mathrm{~m}$. The four sides were set as the roller boundary, and the bottom was fixed. The initial gas pressure of the coal seam was specified as $1.5 \mathrm{MPa}$. The roadway wall was set as a Dirichlet boundary with a given pressure of $0.1 \mathrm{MPa}$ to simulate atmospheric pressure, and the four sides of the coal seam and the coal-rock interface were set as a nonflow boundary.

The other parameters used as inputs to the model are listed in Table 1.

The results of field tests in Zhongliangshan coal mine showed that three occurrences of impact sound caused by outburst were detected, at $2.5 \mathrm{~s}, 3.5 \mathrm{~s}$, and $4 \mathrm{~s}$ after blasting

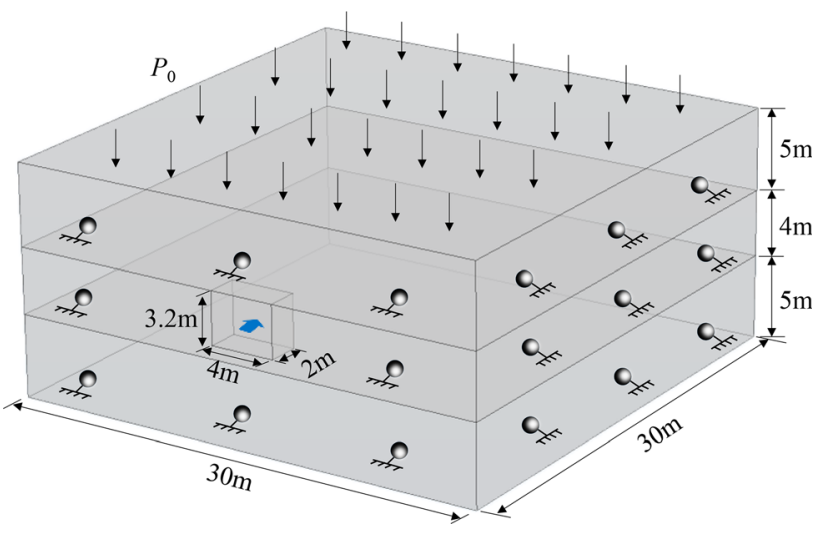

Fig. 5 Physical model for simulating outburst

( $\mathrm{Lu}$ et al. 2019). In this work, the distribution of the risk identification index $C_{\mathrm{m}}$ of outburst in the coal ahead of the working face was analyzed using the time point $2 \mathrm{~s}$ after excavation as an example; the results are shown in Fig. 6. According to calculations with the new model, $C_{\mathrm{m}}$ was greater than $60\left(C_{\mathrm{m}} \gg 1\right)$ on the coal wall, indicating a high outburst risk. With increasing distance from the coal wall, $C_{\mathrm{m}}$ decreased sharply to 1 at a point $1.17 \mathrm{~m}$ from the coal wall $(x=3.17 \mathrm{~m})$. The above analyses demonstrate that in this case, extrusion or outburst occurred in coal within approx. $1.2 \mathrm{~m}$ of the working face, consistent with the fact that eight outbursts occurred in practice. However, when the effects of coal failure were ignored, $C_{\mathrm{m}}$ at any position ahead of the working face was lower than 1 (red dotted line in Fig. 6), indicating that instability would not occur in this case; this result was contrary to the actual

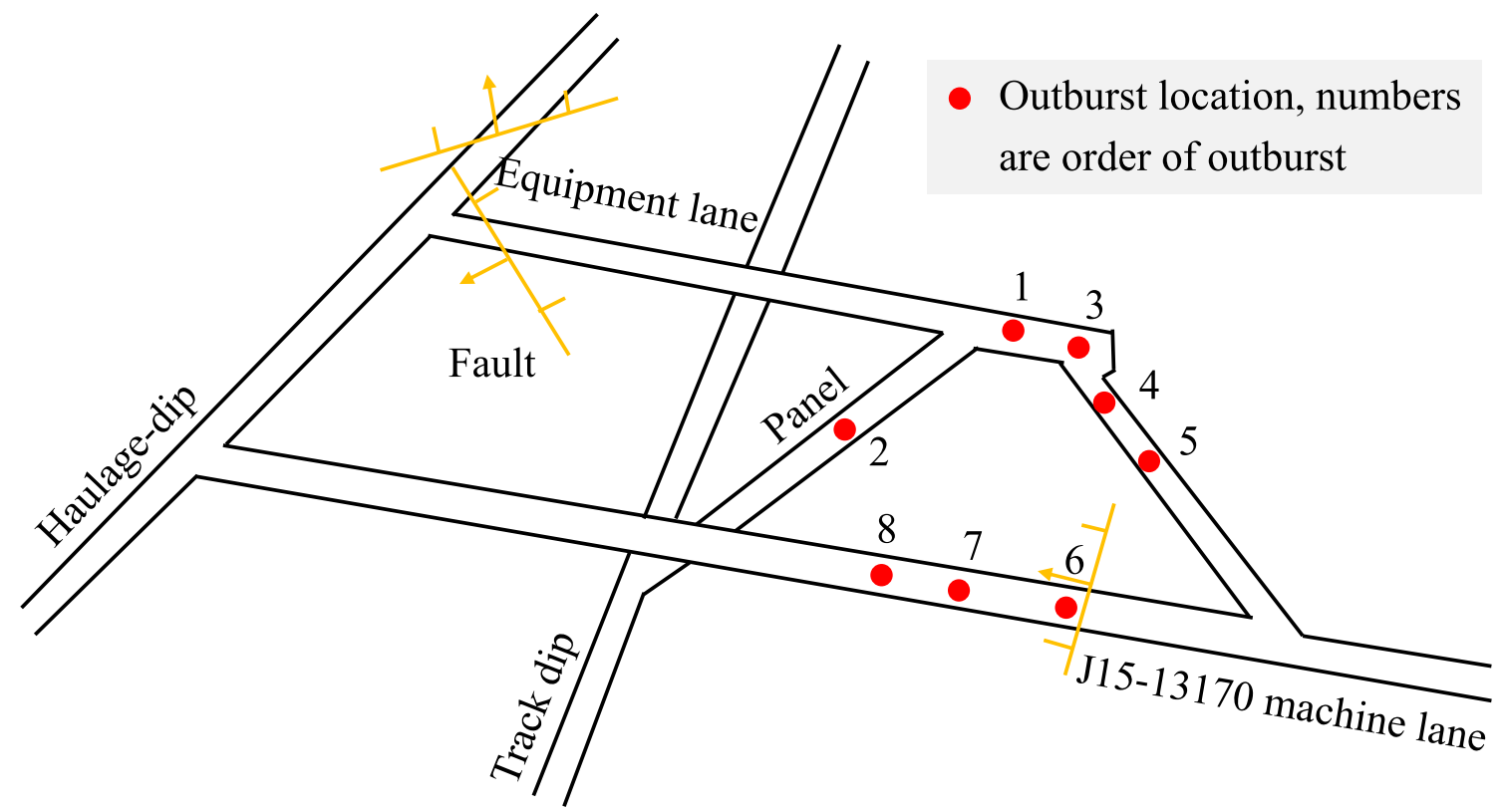

Fig. 4 Locations of the eight outbursts in J15-13,170 machine equipment lanes in No. 8 coal mine 
Table 1 Input parameters for the model

\begin{tabular}{lll}
\hline Parameter & Value & Source \\
\hline Elastic modulus of coal, $E_{0}(\mathrm{GPa})$ & 0.93 & Laboratory test \\
Poisson's ratio of coal, $v$ & 0.29 & Laboratory test \\
Elastic modulus of coal matrix, $E_{\mathrm{m}}(\mathrm{GPa})$ & 8.4 & Xia et al. $(2014)$ \\
Density of coal, $\rho\left(\mathrm{kg} / \mathrm{m}^{3}\right)$ & 1220 & Laboratory test \\
Sorption time of coal, $\tau(\mathrm{d})$ & 0.52 & Liu et al. (2018) \\
Langmuir volume, $V_{\mathrm{L}}\left(\mathrm{m}^{3} / \mathrm{kg}^{1}\right)$ & 0.019 & Laboratory test \\
Langmuir pressure, $p_{\mathrm{L}}(\mathrm{MPa})$ & 2.38 & Laboratory test \\
Initial permeability of coal, $k_{0}\left(\mathrm{~m}^{2}\right)$ & $4.87 \times 10^{-18}$ & Laboratory test \\
Initial fracture porosity of coal, $\varphi_{\mathrm{f} 0}$ & 0.008 & Laboratory test \\
Initial matrix porosity of coal, $\varphi_{\mathrm{m} 0}$ & 0.069 & Laboratory test \\
Maximum sorption strain, $\varepsilon_{\mathrm{L}}$ & 0.01266 & Xia et al. $(2014)$ \\
Plastic strain at starting point of residual stage, $\varepsilon_{\mathrm{bc}}{ }^{\mathrm{p}}$ & 0.032 & Laboratory test \\
Cohesion of coal, $C_{0}(\mathrm{MPa})$ & 0.8 & Laboratory test \\
Internal friction angle, $\varphi\left({ }^{\circ}\right)$ & 27 & Laboratory test \\
\hline
\end{tabular}

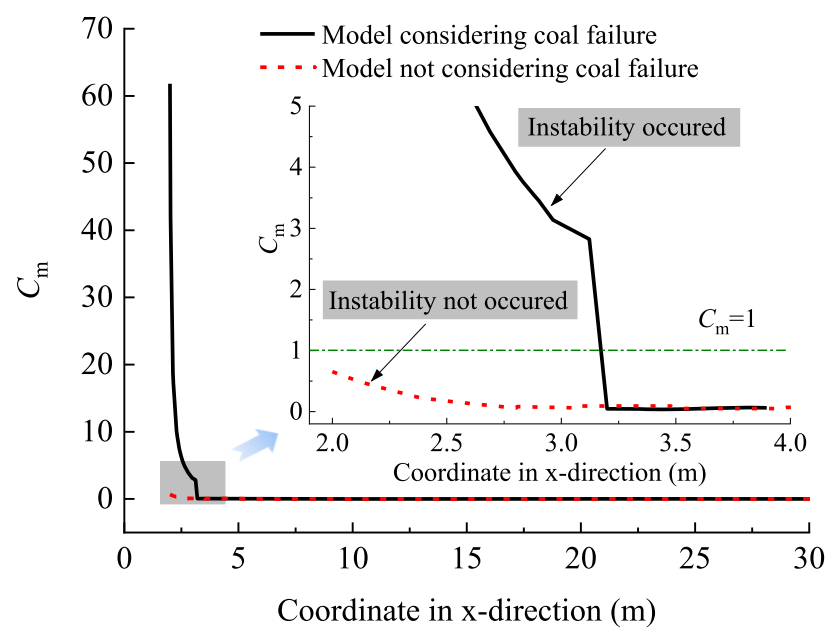

Fig. 6 Distribution of $C_{\mathrm{m}}$ in coal ahead of the working face

observations. This comparison demonstrates the superiority of the new model and the critical outburst criterion.

\section{Mechanism of multiphysics-coupling-induced outburst}

\subsection{Main factors controlling $C_{\mathrm{m}}$}

The critical criterion in Eq. (17) shows that outburst is mainly controlled by stress and its gradient, the coal strength, and the gas pressure gradient. Coal permeability also has an important effect on the distribution of gas pressure. Therefore, in this section, we analyze the influence of stress, coal strength, gas pressure, and permeability on $C_{\mathrm{m}}$. The results are shown in Fig. 7 .
As shown in Fig. 7a, $C_{\mathrm{m}}$ initially decreased slightly, followed by a sharp increase with increasing $\sigma_{\mathrm{v}}$. When $\sigma_{\mathrm{v}}$ increased from 4 to $6 \mathrm{MPa}, C_{\mathrm{m}}$ decreased from 0.93 to 0.74 . Thereafter, when $\sigma_{\mathrm{v}}$ rose to $13 \mathrm{MPa}, C_{\mathrm{m}}$ increased sharply to 16.72 . This was because when $\sigma_{\mathrm{v}}$ is relatively low (corresponding to a small buried depth), coal failure will not occur. In this case, the shear strength of the coal seam increases with an increase in stress, resulting in a low risk of outburst. When $\sigma_{\mathrm{v}}$ is relatively high (corresponding to a large buried depth), the coal seam is easily damaged as the stress increases, and outburst is more likely to occur in this case.

Figure $7 \mathrm{~b}$ and $\mathrm{c}$ show the changes in $C_{\mathrm{m}}$ with cohesion $C_{0}$ and internal friction angle $\phi$. Overall, $C_{\mathrm{m}}$ showed an initial rapid decrease, followed by a gentle reduction as $C_{0}$ and $\phi$ increased. When $C_{0}$ increased from $0.5 \mathrm{MPa}$ to $1 \mathrm{MPa}, C_{\mathrm{m}}$ decreased from 9.08 to 1.15 , but when $C_{0}$ increased from 1 to $2 \mathrm{MPa}, C_{\mathrm{m}}$ was only reduced by 0.69 . When $\phi$ increased from $23^{\circ}$ to $30^{\circ}, C_{\mathrm{m}}$ decreased from 3.51 to 0.56 , whereas when $\phi$ increased from $30^{\circ}$ to $40^{\circ}$, $C_{\mathrm{m}}$ was only reduced by 0.1 . This was because increases in $C_{0}$ and $\phi$ enhance the ability of coal to resist instability, thereby reducing the risk of outburst. When $C_{0}$ and $\phi$ are small, coal is prone to failure. With increasing $C_{0}$ and $\phi$, the ability of coal to resist failure increases rapidly, and the risk of outburst decreases significantly. When $C_{0}$ and $\phi$ are large, coal is unlikely to fail; in this case, increases in $C_{0}$ and $\phi$ have little effect on the outburst risk.

As shown in Fig. $7 \mathrm{~d}, C_{\mathrm{m}}$ increased with as the gas pressure $p_{\mathrm{fo}}$ increased. When $p_{\mathrm{fo}}$ increased from $0.2 \mathrm{MPa}$ to $3 \mathrm{MPa}, C_{\mathrm{m}}$ rose from 0.29 to 2.34 . In this case, when the gas pressure is lower than 1.4 MPa, outburst will not occur.

Figure $7 \mathrm{e}$ shows the change in $C_{\mathrm{m}}$ with the initial permeability of the coal seam, $k_{0}$. In general, the lower the 

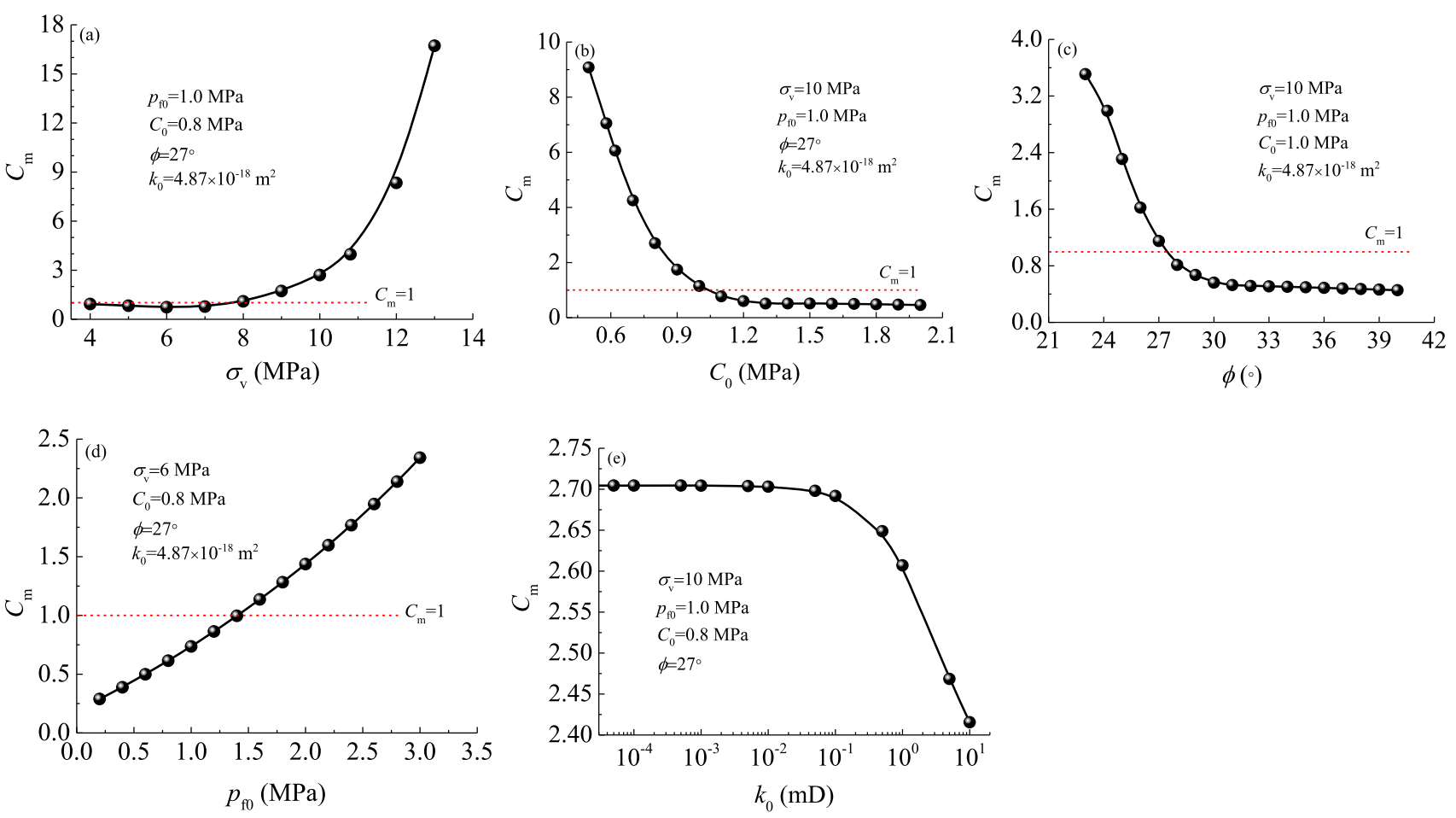

Fig. 7 Effects of various factors on $C_{\mathrm{m}} . \mathbf{a} \sigma_{\mathrm{v}} ; \mathbf{b} C_{0} ; \mathbf{c} \phi ; \mathbf{d} p_{\mathrm{f} 0} ; \mathbf{e} k_{0}$

permeability of the coal, the higher the risk of coal instability. That is, a coal seam with low permeability is more prone to outburst. When $k_{0}$ increased from $10^{-5} \mathrm{mD}$ to $10 \mathrm{mD}, C_{\mathrm{m}}$ decreased from 2.7 to 2.42 , with a reduction of less than $10 \%$. This implies that the effect of permeability on $C_{\mathrm{m}}$ is not significant compared with those of the vertical stress, cohesion, internal friction angle and gas pressure.

\subsection{Multi-factor coupling model of $C_{\mathrm{m}}$}

The above results indicate that stress, coal strength, and gas pressure are the key factors affecting outburst; however, these factors are not independent of each other. In this section, based on the response surface method (RSM), we study the change of $C_{\mathrm{m}}$ under a multi-factor coupling effect and develop a multi-factor coupling model for $C_{\mathrm{m}}$.

The central composite design module embedded in Design-Expert 12 was used for the design, with four factors and three levels, and a total of 30 sets of parameter combinations were obtained. Through numerical calculations, the values of the risk identification index $C_{\mathrm{m}}$ under the corresponding conditions were obtained. Using RSM, we obtained the following multi-factor coupling model for $C_{\mathrm{m}}$ :

$$
\begin{aligned}
C_{\mathrm{m}}= & 7.84+1.66 \sigma_{\mathrm{v}}-15.28 C_{0}-0.24 \phi+1.52 p_{\mathrm{f} 0} \\
& -0.55 \sigma_{\mathrm{v}} C_{0}-0.07 \sigma_{\mathrm{v}} \phi \\
& -0.12 \sigma_{\mathrm{v}} p_{\mathrm{f} 0}+0.60 C_{0} \phi+0.07 \sigma_{\mathrm{v}}^{2} \quad\left(R^{2}=0.912\right)
\end{aligned}
$$

The fitting coefficient of this model was $R^{2}=0.912$, indicating that the model matched well with the numerical results. In addition, the corresponding $p$-values of all items in the model were less than 0.05 , indicating that the effects of each item in the model on $C_{\mathrm{m}}$ were significant.

Equation (18) indicates that interactions exist between $\sigma_{\mathrm{v}}$ and $C_{0}, \sigma_{\mathrm{v}}$ and $\phi, \sigma_{\mathrm{v}}$ and $p_{\mathrm{f} 0}$, and $C_{0}$ and $\phi$, as shown in Fig. 8. The shape of the surface directly reflects the intensity of the interactions between the factors; the larger the curvature of the surface, the stronger the interaction.

As shown in Fig. 8a, as $\sigma_{\mathrm{v}}$ increased, $C_{\mathrm{m}}$ initially decreased, followed by an increase; by contrast, it decreased monotonically with increasing $C_{0}$, consistent with the results shown in Fig. 7a and b. With increasing insitu stress, the response surface became steeper, indicating that the greater the buried depth of the coal seam, the more significant the influence of $C_{0}$ on outburst. With decreasing $C_{0}$, the effect of in-situ stress on $C_{\mathrm{m}}$ became more significant, indicating that the effect of in-situ stress on the outburst risk of soft coal seam was more significant. The contour of $C_{\mathrm{m}}=1$ shows that with increasing $\sigma_{\mathrm{v}}$, the critical value of $C_{0}$ corresponding to coal instability initially decreased and then increased, indicating that the coal strength corresponding to outburst is not a constant but changes with the stress state. Converting the shear strength $\left(C_{0}\right.$ and $\left.\phi\right)$ into Protodyakonov's coefficient $f$ $\left(f=C_{0} \cos \phi / 5(1-\sin \phi)\right.$, which can be derived based on the definition of $f$ and the relation between the uniaxial 

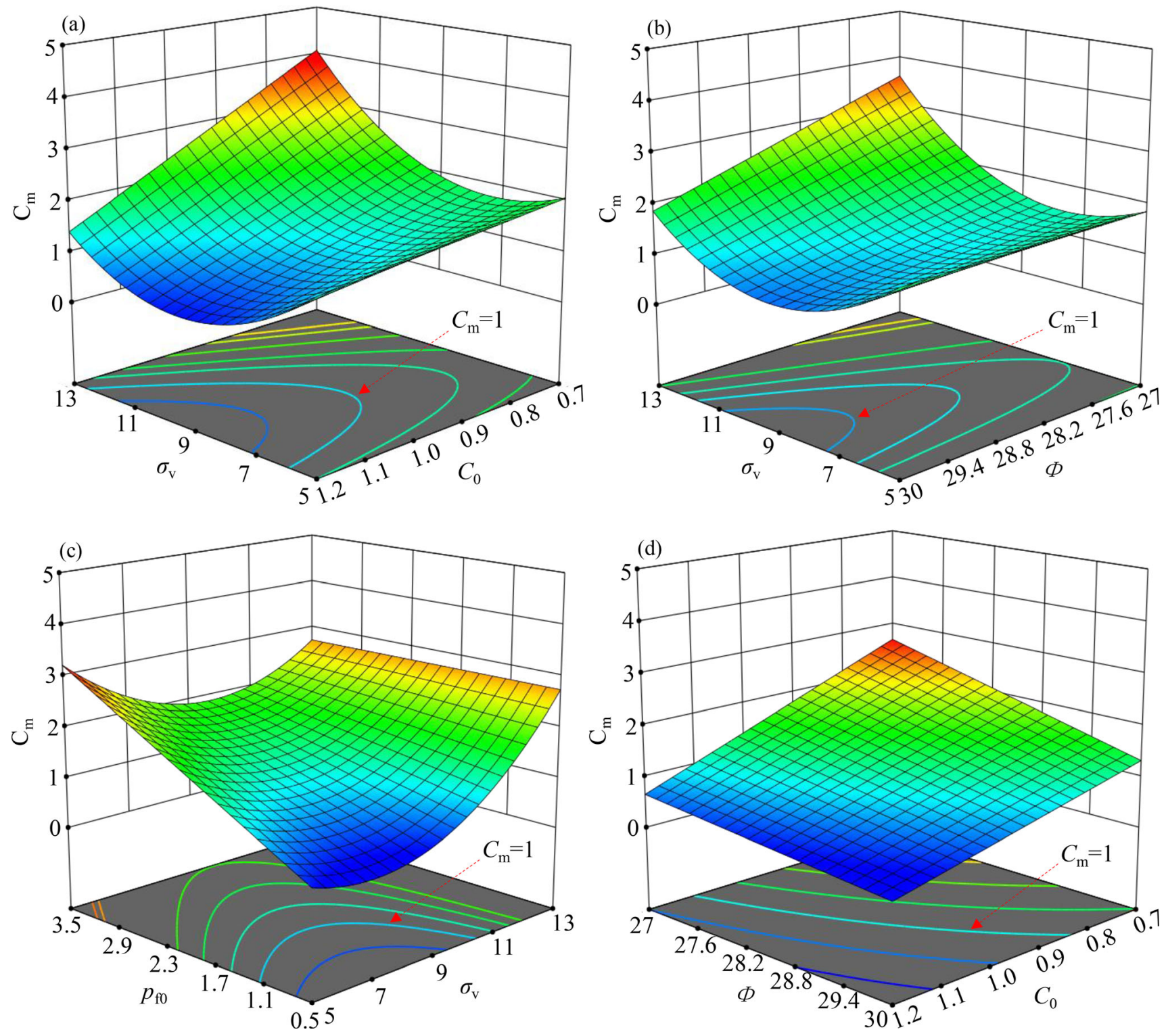

Fig. 8 Effects of interactions of different factors on $C_{\mathrm{m}}$. $\mathbf{a} \sigma_{\mathrm{v}}$ and $C_{0} ; \mathbf{b} \sigma_{\mathrm{v}}$ and $\phi ; \mathbf{c} \sigma_{\mathrm{v}}$ and $p_{\mathrm{f} 0} ; \mathbf{d} C_{0}$ and $\phi$

compressive strength and shear strength), it can be seen that when $\sigma_{\mathrm{v}}$ increased from $6.5 \mathrm{MPa}$ to $8 \mathrm{MPa}$, the critical value of $f$ reduced from 0.36 to 0.32 . Thereafter, it increased continuously, and when $\sigma_{\mathrm{v}}=12 \mathrm{MPa}$, the critical value of $f$ was greater than 0.4 . Figure $8 \mathrm{~b}$ shows that the effects of $\sigma_{\mathrm{v}}$ and $\phi$ on $C_{\mathrm{m}}$ were similar to those shown in Fig. 8a.

As shown in Fig. 8c, with increasing stress, $C_{\mathrm{m}}$ initially decreased and then increased, whereas with increasing gas pressure, $C_{\mathrm{m}}$ increased monotonically. With decreasing insitu stress, the effect of gas pressure on $C_{\mathrm{m}}$ became more significant; conversely, with decreasing gas pressure, the effect of in-situ stress on $C_{\mathrm{m}}$ became more significant. As can be seen from the contour of $C_{\mathrm{m}}=1$, with increasing $\sigma_{\mathrm{v}}$, the critical gas pressure initially increased, followed by a decrease, indicating that the gas pressure corresponding to an outburst is not a constant but changes with the stress state. For example, when $\sigma_{\mathrm{v}}=6 \mathrm{MPa}$, the critical gas pressure was $1.7 \mathrm{MPa}$; when it increased to $8 \mathrm{MPa}$, the critical gas pressure increased to $2.0 \mathrm{MPa}$; with a further increase of $\sigma_{\mathrm{v}}$ to $10.5 \mathrm{MPa}$, the critical gas pressure reduced to $0.5 \mathrm{MPa}$ and thereafter decreased continuously as $\sigma_{\mathrm{v}}$ continued to increase.

As shown in Fig. 8d, with increasing $C_{0}$ and $\phi, C_{\mathrm{m}}$ decreased monotonically, consistent with the results shown in Fig. $8 \mathrm{~b}$ and c. The response surface was approximately planar, implying a relatively weak interaction. Moreover, in different coals, the cohesion and internal friction angle usually decrease or increase at the same time. Therefore, the interaction between them is not discussed here. 
In summary, the critical value of the parameters corresponding to outburst are not constants but depend on the environment of the coal seam. The main conclusions drawn in this section can be used to reasonably interpret the phenomenon of low-index outburst encountered in mining practice. In March 2014, a major outburst occurred in the 21,010 machine roadway of Yuxi coal mine in Yunnan province, China. This incident involved outburst amounts of coal and gas of $970 \mathrm{t}$ and $31,381 \mathrm{~m}^{3}$, respectively. The buried depth of the outburst site was $498 \mathrm{~m}$, and the vertical stress was $\sim 10.6 \mathrm{MPa}$. The gas content and gas pressure were in the ranges $3.16-5.63 \mathrm{~m}^{3} / \mathrm{t}$ and 0.06-0.28 MPa, respectively, and the $f$ value was in the range $0.11-0.27$ with an average value of 0.19 . Importantly, the outburst occurred despite the gas pressure being much lower than the critical value of $0.74 \mathrm{MPa}$ given in the Regulations on Prevention and Control of Coal and Gas Outburst of China. Given the high vertical stress and low $f$ value, we can deduce that the critical gas pressure corresponding to outburst in this case was much lower than $0.74 \mathrm{MPa}$.

\subsection{Mechanism of multiphysics-coupling-induced outburst and method for its control}

Previous research has shown that outburst is the result of the co-action of stress, gas pressure, and coal strength. When the driving force is greater than the resistance, coal instability occurs. However, there has been no clear explanation of how an outburst occurs as a direct consequence of the interactions among stress, gas pressure, and coal strength. In this section, we attempt to determine the mechanism of outburst from the perspective of multiphysics coupling, and propose a classified control method.

Figure 9a depicts the initiation process of an outburst. During mining, when a virgin coal seam is exposed, physical parameters including stress and gas pressure, and the mechanical properties of the coal ahead of the working face retain their original values. With increasing exposure time, the physical properties ahead of the working face interact and adjust dynamically. The interactions among stress, gas pressure, and coal strength are presented in Fig. 9b. The change in stress results in coal failure and creates a highly fractured zone ahead of the working face. In this fractured zone, the permeability of the coal increases greatly, and gas is rapidly released from the coal seam, which greatly alters the gas pressure distribution. Furthermore, the stress concentration ahead of the working face leads to an increase in gas pressure in the corresponding zone, which in turn intensifies the driving force of the outburst. In addition, in the damaged zone ahead of the working face, the coal strength is weakened because of plastic deformation, which in turn reduces the resistance against outburst. Changes in gas pressure distribution can also affect the coal deformation that occurs ahead of the working face, which indirectly affects the coal strength. During the adjustment of the physical properties, if the distributions of these properties meet the critical criterion for outburst, coal instability occurs and initiates an outburst. After the first ejection of unstable coal, outburst develops via a domino effect until the critical criterion is no longer satisfied.

Based on the mechanism of multiphysics-coupling-induced outburst, we divide outbursts into the following four types according to their controlling factors and recommend corresponding control methods, as depicted in Fig. 9c.

Type I: stress-dominated outburst. This type of outburst occurs when the buried depth of the corresponding coal seam is large and it is subjected to relatively high stress. The main factor controlling coal instability is the stress gradient. In this type of coal seam, the outburst risk can be significantly reduced by measures such as protective seam mining or borehole stress relief.

Type II: coal-strength-dominated outburst. This type of outburst tends to occur in a coal seam that is located in a tectonic area with low strength (usually called a soft coal seam). In this type of coal seam, reservoir modification measures such as grouting reinforcement can be adopted to enhance the coal strength and thereby reduce the outburst risk.

Type III: gas-pressure-dominated outburst. This type of outburst usually occurs in a coal seam with a small buried depth and a dense roof and floor. Owing to the good storage conditions, the gas pressure is relatively high. In this type of coal seam, artificial measures to enhance gas drainage can significantly reduce the risk of outburst.

Type IV: multi-factor compound outburst. These outbursts usually occur in coal seams that are deeply buried, with a high gas pressure and a low strength, which have a high risk of outburst. It is difficult to achieve an ideal outburst elimination effect using a single measure in this type of coal seam. Therefore, a trinity of comprehensive measures comprising stress relief, gas drainage, and reservoir modification should be adopted to eliminate the risk of outburst.

\section{Conclusions}

In this work, we developed a multiphysics coupling model and a critical criterion for outburst. The factors controlling the outburst risk identification index in this model were discussed. The main conclusions are as follows.

The multiphysics coupling model was developed based on the equivalent fractured coal model. This model systematically considers coal failure induced by mining, 


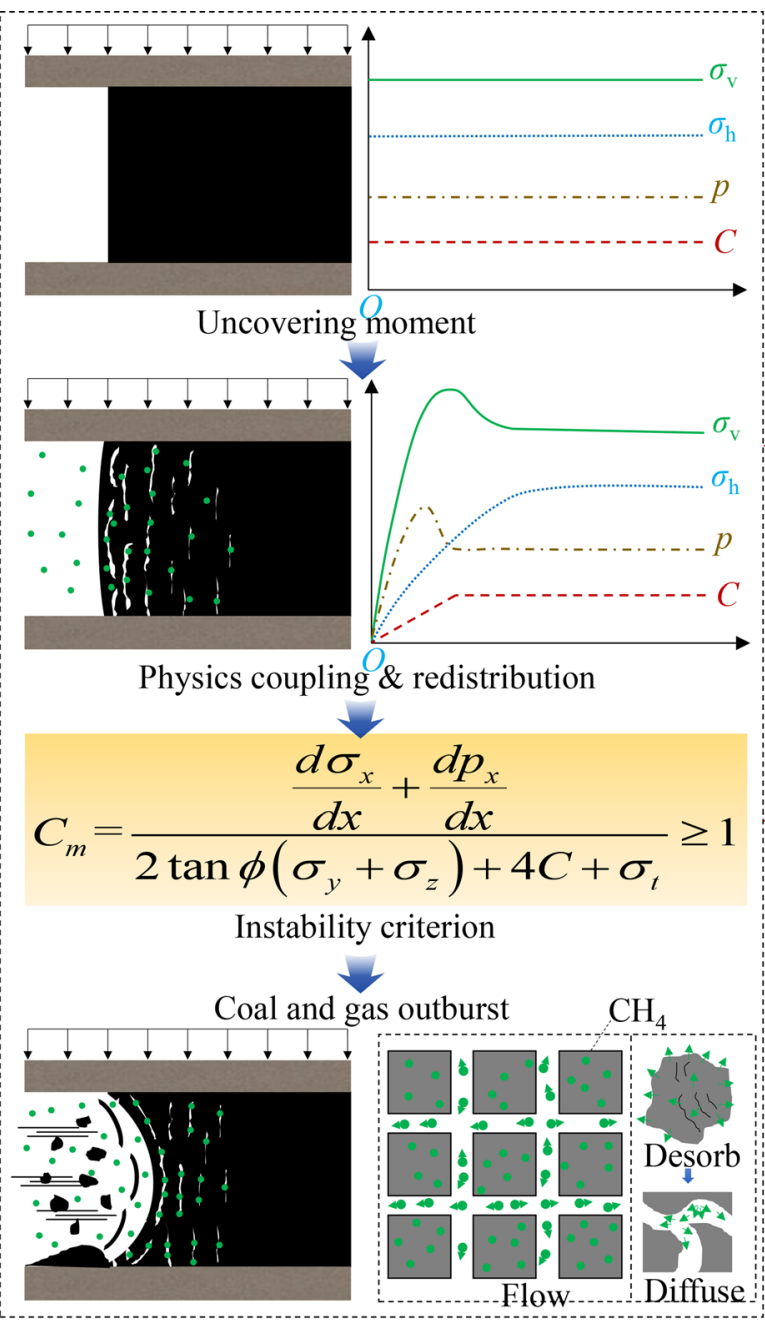

(a) Diagram of coal and gas outburst process

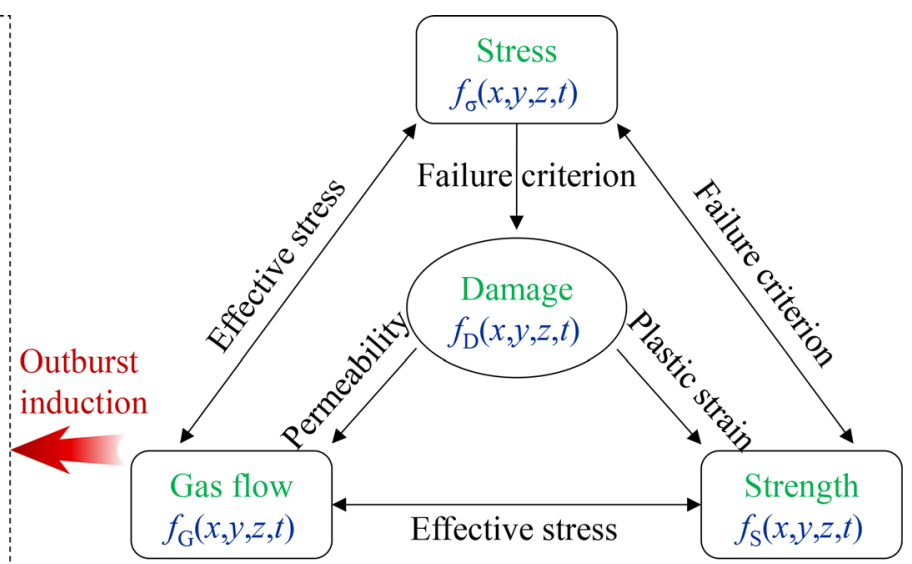

(b) Physics coupling during development of coal and gas outburst

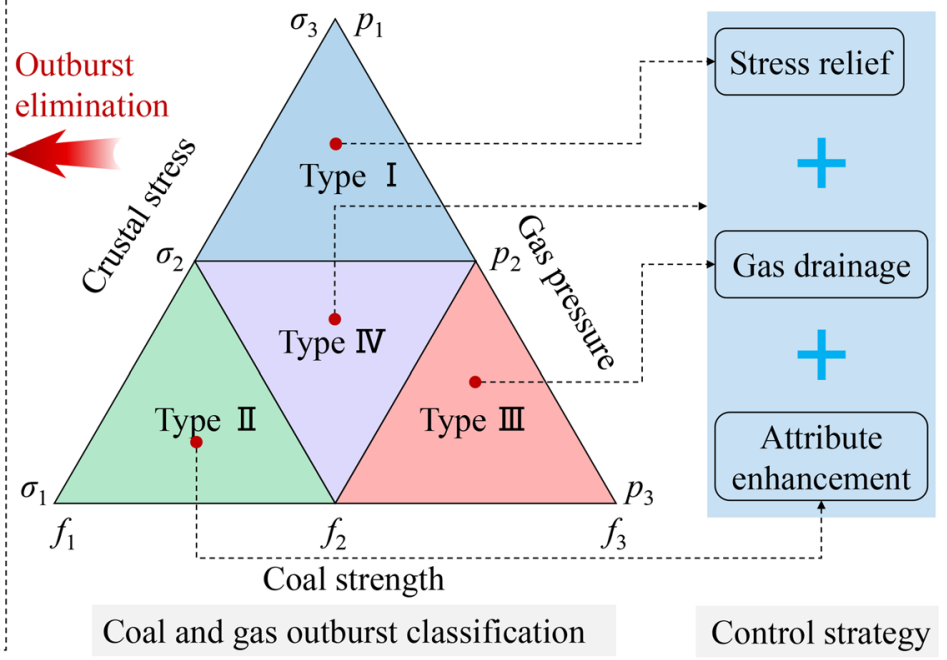

(c) Classified control technique for coal and gas outburst

Fig. 9 Mechanism of multiphysics-coupling-induced outburst and its classified control method

weakening of coal strength in a mining-disturbed zone, and effects of coal failure on mass transfer of gas. The results of the calculations indicate that there is a high risk of outburst in the J15-13,170 machine roadway of the No. 8 coal mine, consistent with the engineering practice.

Based on force analysis of coal ahead of the working face, we propose a risk identification index $C_{\mathrm{m}}$ and a critical criterion for outburst. According to this index, the driving force for an outburst consists of stress gas pressure gradients along the heading direction of the roadway, whereas the outburst resistance depends on the shear and tensile strengths of the coal. The results show that $C_{\mathrm{m}}$ decreases slightly followed by a rapid increase with increasing vertical stress, whereas it increases monotonically with increasing gas pressure and decreases with increasing coal strength.

Multiphysics coupling changes the critical values of parameters corresponding to an outburst. With increasing buried depth, the critical values of gas pressure and coal strength initially decrease slightly, followed by a rapid increase. Therefore, the critical values of parameters corresponding to outburst are not constants but should be determined according to the specific environment of the coal seams.

Based on its controlling factors, outburst can be divided into four types: stress-dominated outburst, coal-strengthdominated outburst, gas-pressure-dominated outburst, and multi-factor compound outburst. Using this classification, a classified control method is proposed to enable a more targeted approach to outburst prevention.

Acknowledgements This work was supported by the National Natural Science Foundation of China (52004276), National Postdoctoral Program for Innovative Talents (BX20190369), Natural Science Foundation of Jiangsu Province (BK20200636) and China Postdoctoral Science Foundation (2019M661996). 
Author Contributions TL: Conceptualization, Methodology, Writing-original draft; BL: Methodology, Supervision. XF: Formal analysis, Writing—review \& editing; ALs: Visualization, Writingreview \& editing.

\section{Declarations}

Conflict of interest The authors declare that they have no known competing financial interests.

Open Access This article is licensed under a Creative Commons Attribution 4.0 International License, which permits use, sharing, adaptation, distribution and reproduction in any medium or format, as long as you give appropriate credit to the original author(s) and the source, provide a link to the Creative Commons licence, and indicate if changes were made. The images or other third party material in this article are included in the article's Creative Commons licence, unless indicated otherwise in a credit line to the material. If material is not included in the article's Creative Commons licence and your intended use is not permitted by statutory regulation or exceeds the permitted use, you will need to obtain permission directly from the copyright holder. To view a copy of this licence, visit http://creativecommons. org/licenses/by/4.0/

\section{References}

Alonso E, Alejano LR, Varas F, Fdez-Manin G, Carranza-Torres C (2003) Ground response curves for rock masses exhibiting strain-softening behaviour. Int $J$ Numer Anal Met 27(13):1153-1185

An F, Yuan Y, Chen X, Li Z, Li L (2019) Expansion energy of coal gas for the initiation of coal and gas outbursts. Fuel 235:551-557

Cao W, Shi J, Durucan S, Si G, Korre A (2020) Gas-driven rapid fracture propagation under unloading conditions in coal and gas outbursts. Int J Rock Mech Min 130:104325

Chen KP (2011) A new mechanistic model for prediction of instantaneous coal outbursts-dedicated to the memory of Prof. Daniel D. Joseph. Int J Coal Geol 87(2):72-79

Chen L, Jin X (2012) Study on the applicability of three criteria for slope instability using finite element strength reduction method. Chin Civil Eng J 45(9):136-146

Danesh NN, Chen Z, Aminossadati SM, Kizil MS, Pan Z, Connell LD (2016) Impact of creep on the evolution of coal permeability and gas drainage performance. J Nat Gas Sci Eng 33:469-482

Fan C, Li S, Luo M, Du W, Yang Z (2017) Coal and gas outburst dynamic system. Int J Min Sci Technol 27(1):49-55

Fan C, Elsworth D, Li S, Zhou L, Yang Z, Song Y (2019) Thermohydro-mechanical-chemical couplings controlling $\mathrm{CH}_{4}$ production and $\mathrm{CO}_{2}$ sequestration in enhanced coalbed methane recovery. Energy 173:1054-1077

Guan P, Wang H, Zhang Y (2009) Mechanism of instantaneous coal outbursts. Geology 37:915-918

Jing W, Xue W, Yao Z (2018) Variation of the internal friction angle and cohesion of the plastic softening zone rock in roadway surrounding rock. J China Coal Soc 43(08):2203-2210

Li H, Xiong G, Zhao G (2016) An elasto-plastic constitutive model for soft rock considering mobilization of strength. T Nonferr Metal Soc 26(3):822-834

Liu T, Lin B, Yang W (2017) Impact of matrix-fracture interactions on coal permeability: model development and analysis. Fuel 207:522-532
Liu Q, Cheng Y, Dong J, Liu Z, Zhang K, Wang L (2018) Non-darcy flow in hydraulic flushing hole enlargement-enhanced gas drainage: does it really matter? Geofluids 2018:1-15

Liu T, Lin B, Fu X, Zhu C (2020a) Modeling air leakage around gas extraction boreholes in mining-disturbed coal seams. Process Saf Environ 141:202-214

Liu T, Lin B, Fu X, Liu S (2020) A new approach modeling permeability of mining-disturbed coal based on a conceptual model of equivalent fractured coal. J Nat Gas Sci Eng 79:103366

Liu T, Lin BQ, Fu XH, Zhao Y, Gao YB, Yang W (2021) Modeling coupled gas flow and geomechanics process in stimulated coal seam by hydraulic flushing. Int $\mathbf{J}$ Rock Mech Min Sci 142:104769

Lu S, Wang C, Liu Q, Zhang Y, Liu J, Sa Z et al (2019) Numerical assessment of the energy instability of gas outburst of deformed and normal coal combinations during mining. Process Saf Environ 132:351-366

Luo MK, Fan CJ, Li S et al (2018) Failure criterion of the geological dynamic system of coal and gas outburst. J China Univ Min Technol 47:137-144

Ma Y, He X, Li Z (2020) A unified model with solid-fluid transition for coal and gas outburst and FEMLIP modeling. Tunn Undergr Sp Tech 99:103349

Ma Y, Nie B, He X, Li X, Meng J, Song D (2020b) Mechanism investigation on coal and gas outburst: an overview. Int J Miner Metall Mater 27(7):872-887

Rudakov D, Sobolev V (2019) A mathematical model of gas flow during coal outburst initiation. Int J Min Sci Technol 29(5):791-796

Shu LY, Wang K, Qi QX et al (2017) Key structural body theory of coal and gas outburst. Chin J Rock Mech Eng 36:347-356

Sobczyk J (2011) The influence of sorption processes on gas stresses leading to the coal and gas outburst in the laboratory conditions. Fuel 90(3):1018-1023

Sobczyk J (2014) A comparison of the influence of adsorbed gases on gas stresses leading to coal and gas outburst. Fuel 115:288-294

Wu Y, Liu J, Elsworth D, Siriwardane H, Miao X (2011) Evolution of coal permeability: contribution of heterogeneous swelling processes. Int J Coal Geol 88(2-3):152-162

Wu X, Peng YW, Xu J, Yan Q, Nie W, Zhang TT (2020) Experimental study on evolution law for particle breakage during coal and gas outburst. Int J Coal Sci Technol 7(1):97-106

Xia T, Zhou F, Liu J, Gao F (2014) Evaluation of the pre-drained coal seam gas quality. Fuel 130:296-305

Yang D, Chen Y, Tang J, Jiang C (2021) Comparative experimental study of methods to predict outburst risk when uncovering coal in crosscuts. Fuel 288:119851

Zhai C, Xiang X, Xu J, Wu S (2016) The characteristics and main influencing factors affecting coal and gas outbursts in Chinese Pingdingshan mining region. Nat Hazards 82(1):507-530

Zhi S, Elsworth D (2016) The role of gas desorption on gas outbursts in underground mining of coal. Geomech Geophys Geo-Energy Geo-Resour 2(3):151-171

Zhou AT, Zhang M, Wang K, Elsworth D (2020) Near-source characteristics of two-phase gas-solid outbursts in roadways. Int J Coal Sci Technol. https://doi.org/10.1007/s40789-020-00362-9

Zou Q, Liu H, Zhang Y, Li Q, Fu J, Hu Q (2020) Rationality evaluation of production deployment of outburst-prone coal mines: a case study of Nantong coal mine in Chongqing, China. Safety Sci 122:104515 